\title{
Individual identification of flapper skate Dipturus intermedius using a baited camera lander
}

\author{
S. Benjamins ${ }^{1, *}$, C. J. Fox ${ }^{1}$, K. Last ${ }^{1}$, C. E. McCarty ${ }^{1,2}$ \\ ${ }^{1}$ Scottish Association for Marine Science, Dunstaffnage, Oban PA37 1QA, UK \\ ${ }^{2}$ University of St Andrews, St Andrews KY16 9AJ, UK
}

\begin{abstract}
The ability of baited remote underwater video (BRUV) landers to attract and identify individual flapper skates Dipturus intermedius based on their spot patterns was tested within the Loch Sunart to Sound of Jura Marine Protected Area (MPA). Two BRUV lander designs, baited with a mix of mackerel, herring, squid and octopus, were deployed in 9 different locations at depths between 105 and $133 \mathrm{~m}$ for approx. $2 \mathrm{~h}$ per deployment. The BRUV successfully obtained video footage and still images of flapper skates during 4 deployments. On 6 occasions, skates remained at the bait long enough for us to obtain high-quality video of their dorsal spot patterns. Five individuals, one of which was observed at 2 adjacent landers in quick succession, were all uniquely distinguishable; one female was matched to existing records in a photo-identification catalogue based on images collected by recreational sea anglers within the MPA. BRUVs offer significant potential for studying individual presence, distribution patterns and abundance of flapper skates, independent of fishing/angling efforts. BRUV landers can therefore support monitoring efforts for evaluating long-term conservation management measures for this species.
\end{abstract}

KEY WORDS: Baited remote underwater video $\cdot$ BRUV $\cdot$ Dipturus intermedius $\cdot$ Flapper skate · Management $\cdot$ MPA $\cdot$ Marine protected area $\cdot$ Photo-ID

\section{INTRODUCTION}

The flapper skate Dipturus intermedius is the largest member of the Rajidae family occurring in European waters. It is primarily a benthic species, feeding on a wide range of invertebrates and teleost fishes (Dulvy et al. 2006). The species was historically identified as the common skate $D$. batis, but this species complex has recently been separated into $D$. intermedius and blue skate $D$. flossada (Griffiths et al. 2010, Iglésias et al. 2010, Last et al. 2016). Both flapper and blue skates are known to be highly vulnerable to overfishing due to their large body size, late maturation and low reproductive rates (Brander 1981), and they are currently classified as Critically Endangered throughout their range (Dulvy et al.

\footnotetext{
${ }^{*}$ Corresponding author: steven.benjamins@sams.ac.uk
}

2006). In the UK, flapper skates still occur in western Scottish coastal waters (Neat et al. 2015), where the Loch Sunart to the Sound of Jura Marine Protected Area (LS-SJ MPA) was designated to conserve a major relict population (Scottish Government 2016). The LS-SJ MPA, covering $741 \mathrm{~km}^{2}$, contains a number of deep basins (>100 mi Fig. 1) where flapper skates have long been targeted by recreational sea angling charters using catch-and-release; this activity remains permitted, whereas most of the MPA is now closed to mobile commercial fisheries. Research trawling is not considered appropriate for sampling flapper skates, and alternative monitoring techniques are therefore required to evaluate the success of the MPA management measures and assess these against current baselines (Edgar et al. 2014).

() The authors 2018. Open Access under Creative Commons by Attribution Licence. Use, distribution and reproduction are unrestricted. Authors and original publication must be credited. 
Both external or implanted tags have been used to monitor skates, and these techniques have generated valuable insights into their behaviour, movements, and in some cases population abundance (Little 1995, Wearmouth \& Sims 2009, Neat et al. 2015). Given sufficient numbers of tagged and re-captured skates, this technique can also produce estimates of population size. However, tagging can be expensive, logistically difficult and may raise some ethical concerns (Kohler \& Turner 2001). On the other hand, anglers routinely photograph captured skates before releasing them, and visual comparison of these photos has confirmed that individual skates can be identified based on their dorsal spot patterns across intervals of at least several years (Marshall \& Pierce 2012, Benjamins et al. 2018). A photo-identification (photo-ID) catalogue, based on visual matching of both tagged and untagged skates by trained observers, contained 435 individuals from the LS-SJ MPA at the time of writing (January 2018; see Benjamins et al. 2018 for details on photo-ID methodology). In time, it is hoped that this database will allow independent mark-recapture-based estimates of population abundance to complement ongoing tagging efforts.

All survey methods have biases, which need to be understood to avoid inaccurate population estimates. More information is therefore needed about the potential biases of angling-based photo-ID for it to contribute to monitoring the LS-SJ MPA skate population. Potential concerns include the extent to which capture probability of individual skates is affected by variables such as skate size, age, habitat requirements, spatial distribution of sampling effort and even individual feeding preferences (Marshall \& Pierce 2012). Notably, commercial sea angling tends to favour specific locations based on skippers' local

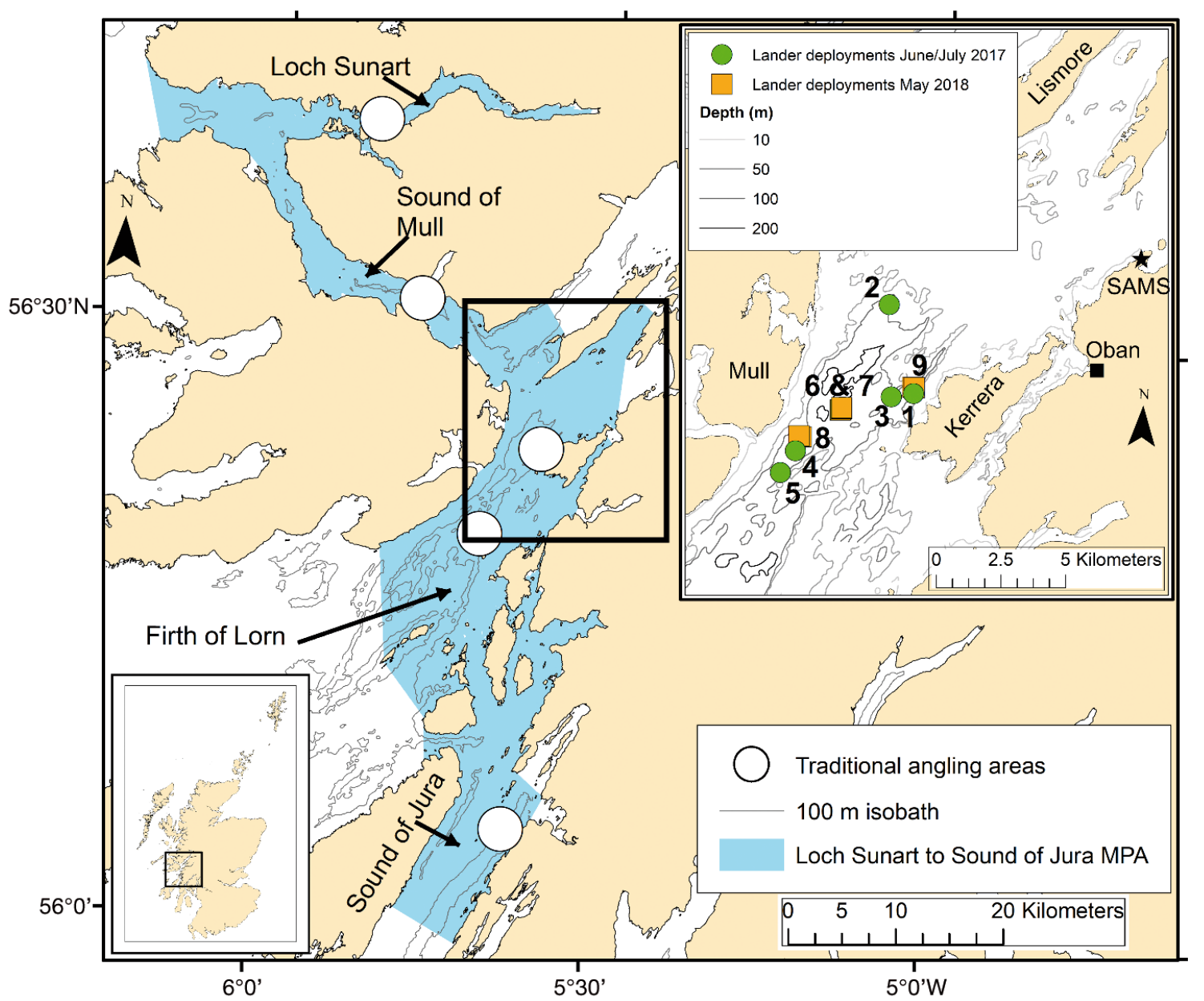

Fig. 1. Overview of the Loch Sunart to the Sound of Jura Marine Protected Area (LS-SJ MPA, in blue), western Scotland. Approximate locations of important traditional angling areas are indicated. Small inset (bottom left): location of LS-SJ MPA within Scotland. Main inset (top right): locations of baited remote underwater video (BRUV) deployments within the northern Firth of Lorn section of the LS-SJ MPA. Black star: location of the Scottish Association for Marine Science (SAMS). Coastline and bathymetry data courtesy of Ordnance Survey UK. MPA data courtesy of Scottish Natural Heritage 
knowledge as well as logistics (e.g. shorter travel time, sites with less exposure to waves; Fig. 1). Angling also tends to be seasonal, with much less activity during winter months. Based on tagging data, at least some skates in the LS-SJ MPA seem to exhibit strong site fidelity (Wearmouth \& Sims 2009, Neat et al. 2015), which potentially challenges the assumption that all skates are equally likely to be caught and tagged/included in the photo-ID catalogue by anglers. Such sampling heterogeneity can violate the assumptions behind mark-recapture models and could result in negatively biased population abundance estimates (Marshall \& Pierce 2012, White \& Cooch 2017). Additional in situ observations, collected independently of sea angling, would therefore assist in evaluating the extent to which angling-associated data might be biased and thereby clarify the utility of current photo-ID sampling as a long-term monitoring tool for flapper skates across the MPA.

Baited underwater camera landers are increasingly being used to study presence, behaviour and abundance of mobile species (Fedra \& Machan 1979, Bailey et al. 2007, Farnsworth et al. 2007, Whitmarsh et al. 2017). Animals are attracted to the lander through a passive odour plume developing downstream, and their presence is captured using video or still photography (Bailey et al. 2007). Increasing availability of inexpensive video cameras has prompted use of the term 'baited remote underwater video (stations)' or BRUVs (Mallet \& Pelletier 2014, Whitmarsh et al. 2017). To date, BRUVs have been used for long-term monitoring of presence and abundance of mobile species, including elasmobranchs, in a number of MPAs (Bond et al. 2012, Speed et al. 2018). Advantages include their unobtrusive and non-extractive nature and relatively low cost, allowing for widespread replication and increased spatial coverage.

This study describes initial results of 9 BRUV deployments involving 2 lander designs in the LS-SJ MPA. The main aim of this study was to test whether high-quality images of flapper skates could be collected that allowed identification of individuals, using both time-lapse still and video cameras, thereby seeking to clarify assumptions surrounding the angling-based photoID approach (Benjamins et al. 2018).

\section{MATERIALS AND METHODS}

Two distinct BRUV lander designs were used in the present study. Initially, a deep-water galvanised steel Kongsberg benthic camera lander designed for longterm observations of macrobenthos (Fig. 2a) was used (BRUV design 1). A GoPro Hero4 video camera (frame rate 23 frames $\mathrm{s}^{-1}$ [fps]; contained within a Scout Pro H3 [Group B Distribution Inc.] deep-water housing) was attached to the lander frame pointing vertically downwards from $1.5 \mathrm{~m}$ above the seabed. This video camera was controlled by a CamDo Blink
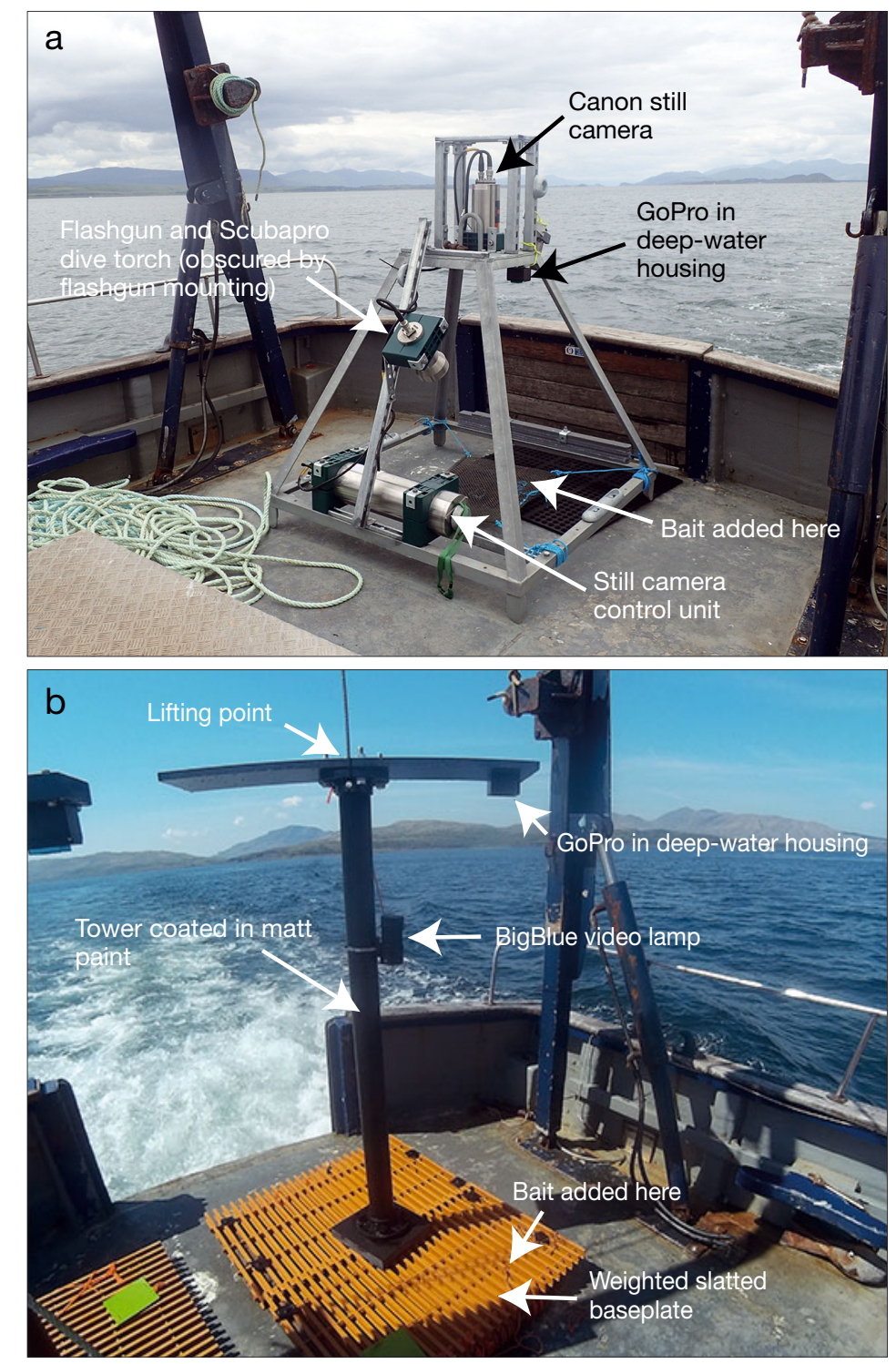

Fig. 2. Annotated comparisons of BRUV designs: (a) BRUV design 1 (2017 deployments); (b) BRUV design 2 (2018 deployments). GoPro video camera and light sources were mounted facing downward in both cases 
time-lapse controller on a $15 \mathrm{~min}$ on and 5 min off duty cycle. The time-lapse controller was used to allow regular cool-down periods, as problems have been reported with GoPro Hero4 cameras overheating and shutting down when in continuous videocapture mode (C. Fox pers. comm.). Continuous illumination was provided by 2 ScubaPro Nova 720 (Johnson Outdoors Inc.) dive torches mounted halfway down the lander and at an oblique angle to the GoPro to reduce backscatter. The video camera was deployed facing vertically downward to ensure clear observations of skates' dorsal surfaces, although this restricted the overall field of view (Whitmarsh et al. 2017). Pre-deployment testing confirmed that illumination was sufficient to allow clear recording of the substrate below the lander at appropriate depths $(\sim 100 \mathrm{~m})$. The lander also contained a downward-facing built-in Canon Powershot G5 5.24 megapixel time-lapse camera (produced by Kongsberg; model OE14-208) with integrated Kongsberg OE11-242 flashgun at $\sim 1.5 \mathrm{~m}$ above the seabed. This camera was programmed to take a photograph (180 dots inch ${ }^{-1}$ [dpi] resolution) every 2 min (the minimum programmable duty cycle).

Following the 2017 deployments, it became apparent that the original lander frame required modification in several respects. Importantly, the space between lander struts (approx. $1.2 \mathrm{~m}$ wide at the base; Fig. 2a) appeared too restrictive for large skates to easily access the bait and be recorded. The second design (BRUV design 2; Fig. 2b) consisted of a central tower supporting a horizontal arm, upon which the Hero4 GoPro was mounted in a downward-facing Scout Pro H3 housing, $135 \mathrm{~cm}$ above the weighted baseplate. Video resolution was as above but the Blink time-lapse controllers were not used, as overheating of the cameras did not appear to be a problem. Because of the single tower design, only a single light could be mounted on each lander. Initial trials showed inadequate illumination from a single Nova 720 torch, so this was replaced with a more powerful BigBlue VL15000P (Bossk International Company Ltd.) wide-angle LED video floodlight placed obliquely $100 \mathrm{~cm}$ above the baseplate (Fig. 2b).

Bait consisted of 2 to 5 whole, thawed mackerel Scomber scombrus, sometimes augmented with 1 to 3 Atlantic herring Clupea harengus, small octopus Eledone cirrhosa or squid Loligo vulgaris, each sliced open to enhance odour plume dispersal, and placed in a mesh bag on the lander's bottom frame (in the centre for BRUV design 1, or along the rim for BRUV design 2). Additional mackerel were sometimes attached to the outside of the bait bag using cable ties to encourage skates to remain beneath the camera. Bait composition was recorded during 2017 deployments but volume and weight were not standardised across deployments; approximate total weights were retroactively estimated as ranging between 560 and $1800 \mathrm{~g}$, based on published length-weight relationship data for S. scombrus (Froese \& Pauly 2018 and references therein). Notably, bait not consumed was recovered for re-use where possible, resulting in increasing amounts of bait in later 2017 deployments. Bait was weighed more consistently during 2018 deployments (mean \pm SD: $945 \pm 216 \mathrm{~g}$ ).

Deployment sites were selected based on bathymetry $(100$ to $150 \mathrm{~m})$, slope $\left(<10^{\circ}\right.$ for lander stability), travel distance and advice from local charter skippers. In total, 9 deployments were made on 5 separate days from the Scottish Association for Marine Science (SAMS) R/V 'Seol Mara' (see Table 1, Fig. 1); the 2018 deployments all involved 2 landers, located approximately $100 \mathrm{~m}$ apart. Each deployment lasted approximately $2 \mathrm{~h}$. Landers were connected to a surface marker float with the R/V 'Seol Mara' remaining close by. Due to logistical constraints, deployments occurred at different times of day and under variable tidal conditions (assessed relative to tides at Oban using the POLTIPS-3 tidal prediction software). Seabird SB19+ vertical cast CTD data (Sea-Bird Electronics) were collected concurrently with the 2018 deployments only, at locations within approx. $100 \mathrm{~m}$ of the landers. Videos and still images were analysed using VLC Media Player v.2.2.6, with animal arrivals and behaviours logged manually. Any high-quality images of observed skates were compared manually to the photo-ID catalogue, using visual matching protocols described by Benjamins et al. (2018). Times of first arrival and maximum number of identifiable individuals observed during the video duration $\left(\operatorname{Max} N_{i}\right.$ i comparable to NMax-A used by Bond et al. 2012) were used to assess relative abundance of the flapper skate at the different deployment sites.

\section{RESULTS}

Both BRUV designs successfully obtained video footage and still images of individually recognisable flapper skates approaching and feeding on the bait at deployment sites 4 and 5 (BRUV design 1; 2 skates each; $\operatorname{Max} N_{i}=$ approx. 0.02 for both deployments; Table 1) and site 8 (BRUV design 2; 1 skate; $\operatorname{Max} N_{i}=$ approx. 0.01 for both landers; Table 1). Only 1 individual was recorded on both the video and still cameras of BRUV design 1 (deployment site 4); all others 
Table 1. BRUV deployments. All 2017 deployments were done using BRUV design 1, and all 2018 deployments using BRUV design 2 (where 2 landers, here identified as 2-1 and 2-2, were deployed in close proximity at each deployment). Max $N_{i}$ : number of individuals observed min ${ }^{-1}$

\begin{tabular}{|c|c|c|c|c|c|c|c|c|c|c|}
\hline $\begin{array}{l}\text { Deploy- } \\
\text { ment } \\
\text { no. }\end{array}$ & $\begin{array}{l}\text { BRUV } \\
\text { design }\end{array}$ & $\begin{array}{c}\text { Lander } \\
\text { no. }\end{array}$ & $\begin{array}{c}\text { Date } \\
\text { (dd/mm/yyyy) }\end{array}$ & Coordinates & $\begin{array}{c}\text { Deployment/ } \\
\text { recovery time } \\
\text { (GMT) }\end{array}$ & $\begin{array}{l}\text { Monitoring } \\
\text { duration } \\
\text { (min) }\end{array}$ & $\begin{array}{l}\text { Depth } \\
\text { (m) }\end{array}$ & $\begin{array}{l}\text { Approx. } \\
\text { tidal phase } \\
\text { at Oban }\end{array}$ & $\begin{array}{c}\text { No. of } \\
\text { skates } \\
\text { identified }\end{array}$ & $\operatorname{Max}_{i}$ \\
\hline 1 & $\# 1$ & 1 & $26 / 06 / 2017$ & $56.400^{\circ} \mathrm{N}, 5.584^{\circ} \mathrm{W}$ & $13: 33 / 15: 23$ & 82 & 128 & Rising & 0 & 0.0 \\
\hline 2 & \#1 & 1 & $30 / 06 / 2017$ & $56.431^{\circ} \mathrm{N}, 5.602^{\circ} \mathrm{W}$ & $10: 30 / 12: 32$ & 92 & 117 & Falling & 0 & 0.0 \\
\hline 3 & \#1 & 1 & $30 / 06 / 2017$ & $56.699^{\circ} \mathrm{N}, 5.598^{\circ} \mathrm{W}$ & $13: 01 / 15: 04$ & 93 & 133 & Falling & 0 & 0.0 \\
\hline 4 & \#1 & 1 & 03/07/2017 & $56.378^{\circ} \mathrm{N}, 5.656^{\circ} \mathrm{W}$ & $09: 42 / 11: 50$ & 94 & 128 & Rising & 2 & 0.0213 \\
\hline 5 & \#1 & 1 & 03/07/2017 & $56.371^{\circ} \mathrm{N}, 5.664^{\circ} \mathrm{W}$ & $12: 52 / 15: 05$ & 99 & 128 & Approx. high tide & 2 & 0.0202 \\
\hline \multirow[t]{2}{*}{6} & \#2 & $2-1$ & $23 / 05 / 2018$ & $56.393^{\circ} \mathrm{N}, 5.629^{\circ} \mathrm{W}$ & $09: 25 / 11: 30$ & 115 & 105 & Rising & 0 & 0.0 \\
\hline & \#2 & $2-2$ & $23 / 05 / 2018$ & $56.393^{\circ} \mathrm{N}, 5.629^{\circ} \mathrm{W}$ & $09: 48 / 11: 50$ & 108 & 112 & & 0 & 0.0 \\
\hline \multirow[t]{2}{*}{7} & \#2 & $2-1$ & $23 / 05 / 2018$ & $56.394^{\circ} \mathrm{N}, 5.628^{\circ} \mathrm{W}$ & $11: 41 / 13: 15$ & 109 & 108 & High tide $\rightarrow$ falling & 0 & 0.0 \\
\hline & \#2 & $2-2$ & $23 / 05 / 2018$ & $56.394^{\circ} \mathrm{N}, 5.628^{\circ} \mathrm{W}$ & $12: 01 / 14: 05$ & 103 & 111 & & 0 & 0.0 \\
\hline \multirow[t]{2}{*}{8} & \#2 & $2-1$ & $25 / 05 / 2018$ & $56.383^{\circ} \mathrm{N}, 5.652^{\circ} \mathrm{W}$ & $09: 37 / 11: 40$ & 109 & 116 & Rising & $1^{\mathrm{a}}$ & $0.0092^{\mathrm{a}}$ \\
\hline & \#2 & $2-2$ & $25 / 05 / 2018$ & $56.384^{\circ} \mathrm{N}, 5.654^{\circ} \mathrm{W}$ & $09: 56 / 12: 00$ & 101 & 111 & & $1^{\mathrm{a}}$ & $0.0090^{\mathrm{a}}$ \\
\hline \multirow[t]{2}{*}{9} & $\# 2$ & $2-1$ & $25 / 05 / 2018$ & $56.403^{\circ} \mathrm{N}, 5.584^{\circ} \mathrm{W}$ & $12: 30 / 14: 35$ & 105 & 116 & Rising $\rightarrow$ high tide & 0 & 0.0 \\
\hline & \#2 & $2-2$ & $25 / 05 / 2018$ & $56.402^{\circ} \mathrm{N}, 5.583^{\circ} \mathrm{W}$ & $12: 45 / 14: 57$ & 120 & 115 & & 0 & 0.0 \\
\hline
\end{tabular}

were solely recorded on the video. The quality of the video was high, and spot patterns were easily distinguished, allowing 5 skates ( 3 females, 2 males) to be individually recognised (Fig. 3). A further 5 brief sightings along the edge of the field of view (using BRUV design 1) could not be used for individual identification. Time of first arrival of each individual varied between 11 and $115 \mathrm{~min}$ after deployment (average: $88 \mathrm{~min})$. Four of the 5 skates undertook multiple (2 to 11) consecutive approaches to the BRUV, each approach lasting $23 \pm 18 \mathrm{~s}$ (mean \pm $\mathrm{SD})$. The single skate observed during deployment 8 (Table 1) visited both landers in succession; it first spent 21 min near the first lander, then took approx. $4.5 \mathrm{~min}$ to traverse the intervening distance of about $100 \mathrm{~m}$ and then spent a further $6 \mathrm{~min}$ around the second lander. Based on a visual comparison to the lander bases, the wingspans of observed skates were estimated to approach or exceed $1 \mathrm{~m}$. Skates appeared to initially approach from downstream, presumably following the bait odour plume (Bailey et al. 2007). One of the female skates was subsequently identified in the photo-ID catalogue as individual \#Di000385 (Fig. 3), having originally been caught and photographed on 19 May 2017 (45 d previ-
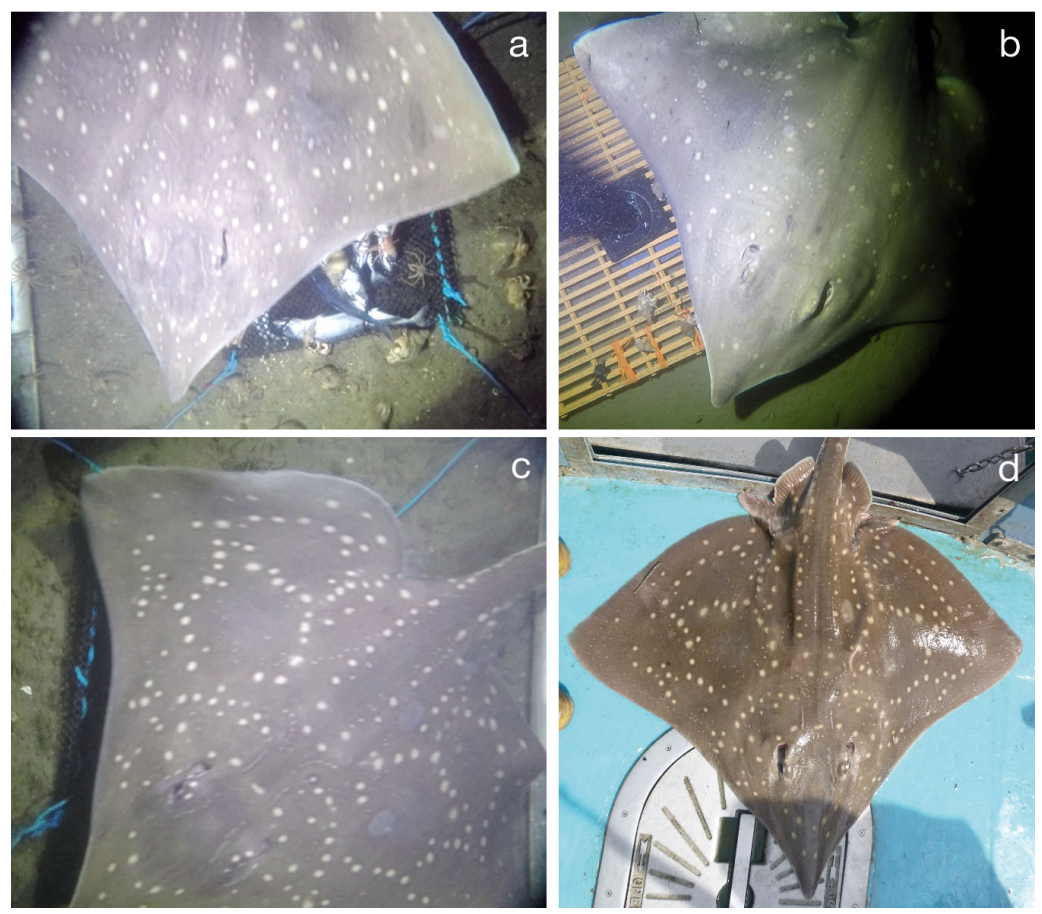

Fig. 3. Examples of flapper skates Dipturus intermedius observed during the experiment $(\mathrm{a}, \mathrm{c})$ in 2017 using BRUV model 1 and (b) in 2018 using BRUV model 2. Note the individual differences in spot patterns. (c) One individual was visually matched to (d) individual Di000385 in the photo-ID catalogue (image copyright R. Campbell) 
4, 5, 6 and 7 appeared coarser, containing more shells and gravel with macroinvertebrate assemblages dominated by hermit crabs Pagurus sp. and squat lobsters Munida sp., as well as assorted bryozoans and cnidarians. Deployment site 8 was characterised by sandy sediments; macroinvertebrate observations were dominated by hermit crabs. In addition to flapper skates, several other elasmobranch and teleost species were observed during the deployments, including spurdog Squalus acanthias, lesser spotted catshark Scyliorhinus canicula, thornback ray Raja clavata, conger eel Conger conger and small gadoids (likely bib Trisopterus luscus and poor cod T. minutus). Although some sediment was briefly resuspended immediately after landing, video quality was generally unaffected by turbidity. Water column temperature and salinity were only recorded for BRUV design 2 deployments in 2018; bottom temperatures were between 8.43 and $8.77^{\circ} \mathrm{C}$ and salinities were between 33.38 and 33.54.

\section{DISCUSSION}

BRUV deployments were successful in repeatedly observing flapper skates, capturing video of sufficient quality to allow identification of individuals through comparison with an angler-based photo-ID catalogue (Mallet \& Pelletier 2014, Benjamins et al. 2018). Multiple brief visits by skates and other mobile species were recorded on the video but missed by the time-lapse still camera of BRUV design 1. Future BRUV-based studies of flapper skates will therefore likely require video rather than time-lapse still cameras to ensure such brief visits are captured, although battery life and memory constraints will likely limit deployment times.

At the time of writing (January 2018), the Scottish skate photo-ID catalogue contained 435 individually identified skates, based on $>800$ photos taken between 2011 and 2017 (as of July 2018, the total sits at 696 individuals). The successful matching of 1 of the 5 identifiable skates observed by the BRUVs with an individual female (Di000385) in the photo-ID catalogue illustrates the utility of using BRUVs to gather additional observational data on this species. Di000385 was first recorded near the island of Kerrera, within the popular angling area along the east side of the Firth of Lorn (Benjamins et al. 2018, Fig. 1), approx. $5 \mathrm{~km}$ from deployment site 4 where she was observed by the BRUV 45 d later. This observation is in line with estimated home ranges of tagged female skates within the LS-SJ MPA (Wear- mouth \& Sims 2009, Neat et al. 2015). This animal was readily identifiable based on her spot pattern, suggesting that patterns are broadly stable irrespective of any increased stress resulting from being landed by anglers (Fig. 3). Observed colour differences comparing the surface and underwater images were likely the result of different illumination intensities and frequencies (dive torch light vs. bright sunlight).

The re-sighting of skate Di000385 by the BRUV, several $\mathrm{km}$ from the main angling areas, suggests that the current angler-based photo-ID and pittagging approach records skates ranging at least several $\mathrm{km}$ across the central Firth of Lorn. Conversely, the 4 other skates identified in the BRUV video have, to date, not been recorded in anglers' photos, suggesting that not all skates may range into angling 'hotspots'. In addition, recent tagging results suggest that male skates may range more widely compared to females (J. Thorburn pers. comm.), so separate population abundance models may need to be developed. Further research is thus needed to assess the impact of skate movements on population abundance estimates derived from different data sources.

Understanding of small-scale distribution and habitat selection among flapper skates is limited (Wearmouth \& Sims 2009, Neat et al. 2015), and it is unclear why several of the lander deployments did not attract any skates. An example is provided by deployment sites 1, 3 and 9, which were deliberately located near a well-known angling location off Kerrera, but where no skates were observed. The reasons for this are unknown, but could include spatiotemporal variation in skate activity, possibly driven by environmental factors such as the tidal cycle. Anecdotal observations by anglers suggest that skate catch rates decline when the tidal currents are strong (R. Campbell pers. comm.; see also Wearmouth \& Sims 2009). The present lander designs did not include a current meter but this would be a valuable addition for future deployments (cf. Taylor et al. 2013).

Other parameters that could influence the attraction of skates to the BRUV include deployment duration, bait type and presentation, illumination characteristics and, possibly, electromagnetic fields generated by metal components of the lander frame (Bassett \& Montgomery 2011, Whitmarsh et al. 2017). Deployment duration could be extended by increasing battery and data storage capacity. The olfactory plume emanating from the lander could be enhanced by further crushing of the bait, whilst standardisation of bait volume and type is also required (Taylor et al. 
2013). Although no obvious responses by skates to the metal components of either BRUV were observed, associated electromagnetic fields could potentially have influenced observations (Kimber et al. 2011). The use of continuous white lighting for the video might have affected the behaviour of some animals, and testing of different wavelengths, including red light, should be considered (Bassett \& Montgomery 2011, Harvey et al. 2012, Fitzpatrick et al. 2013). When skates approached BRUV model 2, it was noted that they were not always fully lit up by the BigBlue LED floodlight due to its beam pointing straight down the central tower. Additional offsetting of the illumination source on the BRUV model 2 may increase the illuminated area around the bait and thereby improve the likelihood of skate identification.

In conclusion, this study has demonstrated that BRUVs can provide a fisheries-independent tool for assessing the presence of the flapper skate (Langlois et al. 2010, Harvey et al. 2012). Furthermore, video quality was sufficient for dorsal spot patterns to be analysed, allowing individual skates to be identified. BRUVs should thus be considered as an additional tool for understanding the distribution and abundance of this species. Such information will be crucial for evaluating the long-term effectiveness of MPAs alongside other conservation measures aimed at protecting the flapper skate.

Acknowledgements. This study was supported through the MASTS Small Grant programme (\#SG394), the COSPIDS grant from Scottish Natural Heritage, the NERC ArcticPRIZE (\#P006086) project and additional sea-time underwritten by SAMS. The skipper and crew of SAMS R/V 'Seol Mara' are thanked for their expertise in lander deployment and retrieval. A. James (SAMS) modified the BRUV design 1 lander to accommodate the GoPro unit, and S. Rodwell (SAMS) assisted in programming and downloading the time-lapse still camera. C. Aitken undertook initial tests with the BRUV design 2 lander as part of his BSc (Hons) degree. Charter skippers R. Campbell, R. Eaton and J. MacGregor provided invaluable advice and support based on their commercial skate angling experience, including provision of photographs of skates to the photo-ID catalogue. We are grateful to the anonymous reviewers for their constructive comments, which greatly improved the manuscript.

\section{LITERATURE CITED}

Bailey DM, King NJ, Priede IG (2007) Cameras and carcasses: historical and current methods for using artificial food falls to study deep-water animals. Mar Ecol Prog Ser 350:179-191

Bassett DK, Montgomery JC (2011) Investigating nocturnal fish populations in situ using baited underwater video: with special reference to their olfactory capabilities. J Exp Mar Biol Ecol 409:194-199
Benjamins S, Dodd J, Thorburn J, Milway VA, Campbell R, Bailey DM (2018) Evaluating the potential of photo-identification as a monitoring tool for flapper skate (Dipturus intermedius). Aquat Conserv Mar Freshw Ecosyst, doi: 10.1002/aqc.2937

Bond ME, Babcock EA, Pikitch EK, Abercrombie DL, Lamb NF, Chapman DD (2012) Reef sharks exhibit site-fidelity and higher relative abundance in marine reserves on the Mesoamerican Barrier Reef. PLOS ONE 7:e32983

* Brander K (1981) Disappearance of common skate Raja batis from Irish Sea. Nature 290:48-49

* Dulvy NK, Notarbartolo di Sciara G, Serena F, Tinti F, Ungaro N, Mancusi C, Ellis J (2006) Dipturus batis. IUCN Red List of Threatened Species, version 2017.2. www.iucnredlist. org/details/full/39397/0 (accessed 29 Sep 2017)

* Edgar GJ, Stuart-Smith RD, Willis TJ, Kininmonth S and others (2014) Global conservation outcomes depend on marine protected areas with five key features. Nature 506: $216-220$

Farnsworth KD, Thygesen UH, Ditlevsen S, King NJ (2007) How to estimate scavenger fish abundance using baited camera data. Mar Ecol Prog Ser 350:223-234

Fedra K, Machan R (1979) A self-contained underwater time-lapse camera for in situ long-term observations. Mar Biol 55:239-246

Fitzpatrick C, McLean D, Harvey ES (2013) Using artificial illumination to survey nocturnal reef fish. Fish Res 146: 41-50

Froese R, Pauly D (eds) (2018) FishBase. www.fishbase.org (accessed 29 May 2018)

* Griffiths AM, Sims DW, Cotterell SP, El Nagar A and others (2010) Molecular markers reveal spatially segregated cryptic species in a critically endangered fish, the common skate (Dipturus batis). Proc R Soc B 277:1497-1503

*Harvey ES, Newman SJ, McLean DL, Cappo M, Meeuwig JJ, Skepper CL (2012) Comparison of the relative efficiencies of stereo-BRUVs and traps for sampling tropical continental shelf demersal fishes. Fish Res 125-126: $108-120$

* Iglésias SP, Toulhoat L, Sellos DY (2010) Taxonomic confusion and market mislabelling of threatened skates: important consequences for their conservation status. Aquat Conserv 20:319-333

Kimber JA, Sims DW, Bellamy PH, Gill AB (2011) The ability of a benthic elasmobranch to discriminate between biological and artificial electric fields. Mar Biol 158:1-8

Kohler NE, Turner PA (2001) Shark tagging: a review of conventional methods and studies. In: Tricas TC, Gruber SH (eds) The behavior and sensory biology of elasmobranch fishes: an anthology in memory of Donald Richard Nelson. Springer, Dordrecht, p 191-224

* Langlois TJ, Harvey ES, Fitzpatrick B, Meeuwig JJ, Shedrawi G, Watson DL (2010) Cost-efficient sampling of fish assemblages: comparison of baited video stations and diver video transects. Aquat Biol 9:155-168

Last PR, Weigmann SI, Yang L (2016) Changes to the nomenclature of the skates (Chondrichthyes: Rajiformes). In: Last PR, Yearsley GK (eds) Rays of the world: supplementary information. CSIRO Publishing, Collingwood, p 11-34

Little W (1995) Common skate and tope: first results of Glasgow Museum's tagging study. Glasg Nat 22:455-466

*Mallet D, Pelletier D (2014) Underwater video techniques for observing coastal marine biodiversity: a review of sixty years of publications (1952-2012). Fish Res 154:44-62 
Marshall AD, Pierce SJ (2012) The use and abuse of photographic identification in sharks and rays. J Fish Biol 80: 1361-1379

Neat F, Pinto C, Burrett I, Cowie L and others (2015) Site fidelity, survival and conservation options for the threatened flapper skate (Dipturus cf. intermedia). Aquat Conserv 25:6-20

Scottish Government (2016) Loch Sunart to the Sound of Jura Nature Conservation Marine Protected Area Order 2016. Scottish Gobernment, Edinburgh. www.legislation. gov.uk/ssi/2016/90/made (accessed 24 Aug 2017)

Speed CW, Cappo M, Meekan MG (2018) Evidence for rapid recovery of shark populations within a coral reef marine protected area. Biol Conserv 220:308-319

Editorial responsibility: Eric Gilman,

Honolulu, Hawaii, USA
Taylor MD, Baker J, Suthers IM (2013) Tidal currents, sampling effort and baited remote underwater video (BRUV) surveys: Are we drawing the right conclusions? Fish Res 140:96-104

Wearmouth VJ, Sims DW (2009) Movement and behaviour patterns of the critically endangered common skate Dipturus batis revealed by electronic tagging. J Exp Mar Biol Ecol 380:77-87

*White GC, Cooch EG (2017) Population abundance estimation with heterogeneous encounter probabilities using numerical integration. J Wildl Manag 81:322-336

* Whitmarsh SK, Fairweather PG, Huveneers C (2017) What is Big BRUVver up to? Methods and uses of baited underwater video. Rev Fish Biol Fish 27:53-73

Submitted: January 2, 2018; Accepted: June 19, 2018 Proofs received from author(s): August 24, 2018 